$\mathrm{V} \Delta \mathrm{K} 351$

ББК 67.401.14

DOI 10.22394/1682-2358-2021-3-35-43

A.I. Glusbkov, Doctor of Sciences (Law), Head of the Criminal Procedure Department, Dubna State University

A.M. Ryabikov, post-graduate student of the Theory of Law Department, Dubna State University, Chief State Customs Inspector of Dubna customs post of Moscow Regional Customs

\section{COUNTERACTION TO OFFICIAL CUSTOMS CRIMES IN THE RUSSIAN EMPIRE IN THE 19TH - EARLY 20TH CENTURIES}

The issue of combating malfeasance in the customs service in the 19th - early 20 th centuries is studied. The reasons for manifestations of corruption on the part of customs officials are identified. Measures taken by the state to prevent corruption are highlighted, and problematic aspects and difficulties in bringing to criminal liability of the designated category of persons were identified. The characteristic of the corruption counteraction is given and the position on the possible implementation of the results of the measures taken in practice in the Russian Federation is indicated.

Key words and word-combinations: official customs crime, customs service, counteraction to malfeasance.
А.И. Глуиков, доктор юридических наук, заведуюший кафедрой уголовного проиесса Государственного университета "Аубна» (етаі): profglushkov@mail.ru)

A.M. Рябиков, аспирант кафедри теории права Государственного университета "Аубна», главньй государственньй таможенньий инспектор таможенного поста Аубна Московской областной mаможни (email: ryabikov.artyom@mail.ru)

\section{ПРОТИВОАЕЙСТВИЕ $\triangle О \Lambda Ж Н О С Т Н Ы М$ ТАМОЖКЕННЫМ ПРЕСТУПАЕНИЯМ РОССИЙСКОЙ ИМПЕРИИ В XIX - HAЧA Е XX ВЕКА}

Аннотация. Исследуется вопрос борьбы с должностными преступлениями в таможенной службе в XIX - начале XX в. Выявляются причины коррупционных проявлений со стороны таможенных служащих. Приводится описание мер по противодействию коррупции и обозначается позиция по возможной реализации результатов проводимых мероприятий на практике в современной России.

Ключевые слова и словосочетания: должностное таможенное преступление, таможенная служба, противодействие должностным злоупотреблениям.

B мюбом современном государстве большое внимание со стороны власти уделяется Аеятельности уполномоченных органов, в том числе структур таможенной службы. Важкнейшими направлениями 
деятельности таможенной служкбы явмяется соблюдение норм законности; недопущение причинения вреда интересам и благам человека, государства и общества в условиях формирования системы таможенной деятельности, которая включает таможенные платежи, таможенный контроль и таможенное оформление.

Вследствие низкой эффективности функционирования государственного аппарата Российской империи в конџе XIX - начале XX в., многочисменных нарушений законодательных норм домжностными мицами всех уровней в стране была разработана стратегия борьбы с противоправными Аеяниями чиновников. Александр I в специальном обращении от 5 августа 1816 г. к Министерству юстиции Российской империи указывал на необходимость пресечения получения должностными циџами государственного органа, обеспечивающего перемещение через границу грузов, материальных ценностей в качестве взятки. Император считал это позором Аля государства, требовал от полицейских всемерно препятствовать «мерзкому михоимству». С 1841 г. в течение восемнадцати мет более ста тысяч чиновников были подвергнуты суровым мерам государственного принуждения. Среди них были и высокопоставменные сотрудники скужбы организации таможенного контромя.

С 1826 г. начал функционировать специальный государственный комитет - предшественник современного Управления по противодействию коррупџии, одной из задач которого явцялась борьба с Аачей и получением взяток. Сотрудники данной структуры изучали причины коррупџии, разрабатывали меры предупреждения осуществления должностными миџами определенных действий в пользу субъектов, которые предоставляли им за это материальные ценности или общественные ценности и блага.

Специалисты комитета выявили и систематизировали причины коррупционных действий чиновников:

- слабую законодательную базу, регулирующую порядок исполнения служебных полномочий сотрудниками государственного органа, обеспечивающего порядок перемешения через таможенную границу грузов;

- низкий уровень материального благосостояния миџ, работающих в таможенной службе;

- несоответствие степени мер государственного принуждения за противоправное деяние степени проступка. К примеру, назначалось оАно и то же наказание за правонарушение, совершенное из-за жадности, в корыстных целях, и за незаконный поступок, вызванный крайней нишетой.

Указывалось, что в случае устранения этих трех причин неправомерных Аействий сотрудников таможни будут предотврашены и иные обстоятельства, провоцирующие дачу и получение взятки. Если же эти причины устранены не будут, все принимаемые меры желаемого результата не Аадут [1] .

Выявление обстоятельств коммерческого подкупа повлекмо за собой необходимость разработки мер наказания за проступки такого рода. Под-

36 Bulletin of the Volga Region Institute of Administration • 2021. Vol. 21. № 3 
готовценная схема основывацась на принџипах постепенности и поступательности мер государственного принуждения.

ОАним из первых занялся вопросом борьбы со взяткодателями и взяточниками в 1826 г. видный государственный деятель, губернатор Иркутска (1805-1806) и Тобольска (1806-1807) А.М. Корнилов, предложивший систему мер по противодействию Аанному виду преступлений. Сенатор полагал, что в основу разработанных им мер Аолжно быть положено понимание специфики взаимосвязи служебных возможностей таможенных чиновников и изменения уровня их материального благосостояния. Он предложил следующие способы преАотвращения коррупџии:

1. Собирать правдивые и подробные данные о материальном благопо-

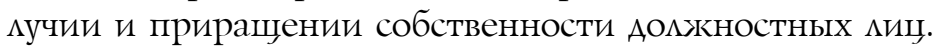

2. Обязать работников почты тайно уведомлять компетентные структуры о получении чиновниками денежных сумм, каких- иибо предметов и об отправке ими денег и вещей на чье-либо имя.

3. САелать именными документы, отражкающие перемещение денежных средств на случай, если нужно будет уличить корыстолюбца посредством, например, описи его имения [2, с. 1-2].

ПреАложенная политиком система была введена в практику борьбы с мздоимством. За должностными миџами, которых подозревали в нечестном поведении, устанавцивали тайный надзор [3].

ОАнако к особо заметным результатам эта борьба не приводила. Объемы взяток росли по причине того, что аппарат таможенной службы быстро приспосабливался к мюбым новым антикоррупџионным мерам. ОАной из причин формирования и развития неправомерного поведения была неповоротливость государственного механизма, регулирующего общественную жизнь. Многочисленные, часто не связанные и Ааже противоречащие Аруг Аругу приказы, распоряжения и инструкции создавами мазейки чиновникам, ставили в позицию беспомощных и униженных обращающихся к ним гражаан.

Примерно с 1860-х годов характер системы борьбы с коррупщией поменялся с карающего на упредительный. Стали активно применяться профилактические меры, целью которых были предотвращение или минимизация причин дачи, а также получения взятки.

КАючевой задачей предупрежАения экономических преступлений в конце XIX - начале XX в. было воспрепятствование росту их числа. С позиции современной правовой науки о преступности нынешняя система государственных мер, направленных на предотвращение совершения новых преступлений, развивающаяся в условиях нового общества, сложилась исторически: она вкцючает предпосылки субъективного и объективного характера, на которых основано сокращение числа противоправных деяний, а также совокупность мер, нейтрализующих факторы, порождающие нарушение законности [4, с. 293]. 
Систему государственных мер по противодействию опасным Амя человека и общества деяниям специалисты по криминологии рассматривают и как явление общесоџиального характера, и как спещиальное понятие изучения противоправных действий. В первом случае речь идет о мюбой полезной для общества деятельности по противодействию нарушениям закона. Во втором случае подразумевается работа полномочных структур по выяснению обстоятельств преступных деяний, выявлению граждан, потенциально способных совершить преступцение и предотврашению таких действий. Оба эти направления профилактики преступлений прослеживаются в борьбе с коррупџией в России на рубеже XIX-XX вв.

Попытки борьбы со взятками преАпринимались государством еще в 1830-х годах. Так, государственные органы ввели коммегиальность при принятии постановлений; утвердились новые формы делопроизводства, что существенно усложнило взаимоотношения просителей и должностных миџ таможенной службы. Но чиновники быстро приспособили новые усАовия к своим корыстным интересам и продолжили порочную практику мздоимства [5, с. 153].

Следующим шагом властей по предотвращению коррупџии стала минимизаџия участия киџ, состоящих на государственной таможенной службе, в хозяйственной деятельности. Установленные ограничения действова-

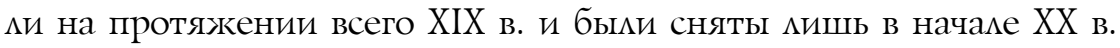

Составляя первый Уголовный кодекс России в 1845 г., сотрудники Второго отделения учии специфику капиталистического строя. Чиновники активно участвовали в деятельности по установлению ответственности Аолжностных миц за незаконное заключение финансовых соглашений. ОАнако масштабного искоренения коррупџии не произошло вслеАствие реАкого и нерегулярного привлечения виновных к юридической ответственности: немногим более 181 человек в 1846 г., 55 - в 1849 г. (более 20 были оправданы, остальные отделались штрафами, замечаниями, выговорами по службе) [6] .

ОАним из способов взятки бымо включение чиновника в состав хо-

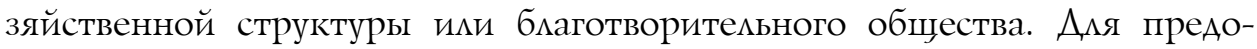
твращения такого рода противоправных действий губернаторы обязаны были следить за тем, чтобы их подчиненные не участвовали в подобных сделках.

Постепенно, к концу XIX столетия, сложилась система ограничений Аля миц, занимающих государственные Аолжности, которая, по мнению российских властей, должна была препятствовать совершению чиновниками Аолжностных преступлений. Таможенным служащим было запрещено: покупать вещи и предметы, порученные им по должности; заключать торговые и иные финансовые сделки мично или через подставных киџ по месту служкбы. Это не позволялось и супругам дмя пресечения змоупотребмений в интересах семьи. 
В создании предприятий промышленности не имели права участвовать служащие 1-3 классов и некоторые должностные лица из специальных списков. Остальные чиновники домжны были получить на это разрешение своего руководства, которое в некоторых случаях пользовалось этим правом в корыстных целях.

САужащий, не уведомивший свое руководство об участии в коммерческом предприятии, должен был подать в отставку. В случае отказа это сделать в течение трех месяџев следовало увольнение без учета его мнения и жекания.

По мнению современных российских цивицистов, некоторым образом

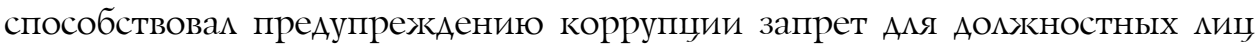
печатать собственные труды о специфике внутренней и внешней политики Российской империи [7, с. 174]. ПосреАством данной меры решались Аве задачи: обеспечивалась государственная безопасность; пресекалось разглашение секретных сведений.

В рамках внедрения в практику мер по профилактике преступлений, совершаемых должностными миџами, А.М. Корнилов в середине 1820-х гоАов разработал порядок определения изменений имущественного положения субъекта, явмяющегося сотрудником таможенной службы, связанных с получением взяток в виде ценных вещей мибо денег. Тайные уведомления со стороны работников почты помогали изобцичать мздоимџев [8].

С конџа 1850-х годов все должностные Аиџа таможни стали отчитываться о наличии собственности у них цично, а также у их супругов, детей, родителей и иных близких родственников. Информация подавалась не в Аепартамент внешней торговли, к которому относилась данная структура, а в администрацию конкретной губернии, на территории которой располагался таможенный пункт [9]. Таким образом достигались Аве цели: во-первых, власть имела полную картину материального благосостояния каждого чиновника; во-вторых, искцючалась коррупция в правительстве империи.

Профилактическую направленность имела также запись в послужной список о том, что должностное Аиџо было привлечено к ответственности за злоупотребление в корыстных целях служебным положением. В этом случае также решались две задачи: граждан, склонных к таким правонарушениям, не брали на государственную службу; а если в силу искмючительных профессиональных данных их принимали на работу в государственный аппарат, то руководство устанавливало жесточайший контроль за Аеятельностью такого служащего в џелях недопущения реџидива правонарушения.

Справедливости ради следует признать, что информация о незаконных действиях, совершенных гражданином в период несения таможенной службб, не всегда вносилась в формулярный список. Согласно специальному указу Сената от 25 апреля 1857 г., в структуру главного документа, 
опредецяющего положение каждого чиновника в системе государственной службы, перестали вносить Аанные о подсуАности, если чиновник вслеАствие Всемицостивейшего Манифеста бым прощен [10, с. 65]. Опубликованию документа предшествоваци запрос МВА, рассмотрение проблемы Сенатом с последующим обращением в Государственный совет.

В целях предотвращения преступлений, посягающих на нормальное функщионирование таможенной службы, с 1904 г. начала устанавциваться благонадежность принимаемых на работу граждан [11, с. 1-3]. Поводом Аля введения Аанной профицактической меры послужили частые возвраты на прежние Аолжности $и ц$ в отношении которых были применены меры государственного принуждения за преступиения экономического характера. В Таможенном департаменте, как одной из наиболее коррумпированных государственных структур, такие проверки стали осуществцяться в первую очередь.

Вслелствие спещифического развития общественных отношений, обусмовленных функщионированием рынка 1880-1890-х годов, выявцять случаи использования служебного положения в корыстных целях стало труАнее. В качестве причины можно назвать соблюдение даже Аля почтового Аепартамента тайны обращения выпущенных в бумажной форме, согласовывающейся с метамиическим запасом страны, денежных знаков, а также денежных документов, свидетельствующих о приобретении прав на часть собственности, которые вносились в содержащие рекомендации письменные заявления, обеспеченные страховыми обществами зарубежных стран [12]. Этот фактор, с точки зрения многих исследователей, позволиц в указанный период русской истории активно реализовывать разного рода коррупционные соглашения [13, с. 25]. Чиновник фактически получал посредством почтового отправцения с ценным вцожением взятку, но Аоказать противоправный характер этого деяния бымо невозможно, поскольку отсутствовац законный механизм антикоррупџионного контроля. Некоторый профихактический эффект по предотврашению таможенных нарушений давали проводимые время от времени проверки соблюдения порядка отправлений, осуществляемых почтовыми предприятиями.

В послеАней трети XIX в. в обязанности самих ведомств были вменены профилактика и пресечение виновных деяний, совершаемых государственными служащими в корыстных целях, посредством применения разцичных мер Аисциплинарного и административного характера. Так, руководители получили право изучать поступки подчиненных, преАъявцять обвинения, требовать объяснений [14, с. 18], а затем принимать решение об аАминистративном разрешении дела мибо о передаче его в суА. ПреАставляется,

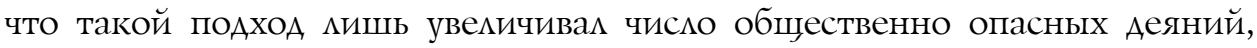

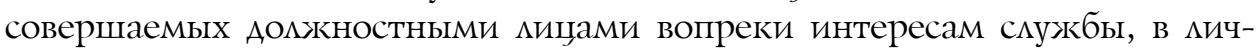
ных корыстных целях. Не способствовало улучшению ситуации огромное количество (более 60\% от общего числа) оправдательных приговоров в

40 Bulletin of the Volga Region Institute of Administration • 2021. Vol. 21. № 3 
отношении мздоимџев. Например, в 1873 г. под суд попали 116 человек, из которых 76 были оправданы [15]. Такая тенденция прослежкивалась фактически до конца XIX в.

Следует отметить особое значение влияния общества на процессы предотврашения и определения домжностных правонарушений. В конџе XIX - начале XX столетия, во времена широкого распространения печатных среАств массовой информации, в печати появмяются исследования и закмючения, касающиеся указанной тематики, в том числе реальные примеры правонарушений из практики с участием должностных миц. ОАнако подобная пубцичность критично воспринимается государственными органами. В России действовал механизм государственного контроля над печатными изданиями, а также существовали штрафные санкции за публикации, где освещались указанные правонарушения. К примеру, в течение 1911 г. периодическое издание «Гроза» получило штрафов на сумму 2600 рублей за статьи о коррупции [16] .

Существенную роль в предотвращении правонарушений со стороны Аолжностных миџ сыграло введение в XIX в. более строгих мер ответственности, касающихся должностных миц в случае их правонарушений. Например, до середины XIX в. благодарность должностному мицу считалась вознаграждением и, соответственно, не приравнивацась к взятке, если Аолжностное миџо офиџиально в течение трех Аней об этом заявцямо. Вместе с тем меры ответственности за такой проступок были весьма мягкими; согласно Уложению о наказаниях уголовных и исправительных 1845 г. они обладали административным характером, а не уголовным. Размер штрафа не мог быть больше удвоенной стоимости самой взятки в случаях, когда взятка была передана уже после фактического должностного правонарушения. Аанная концепция в рамках правового регулирования и правоприменения определяла в действительности свободное

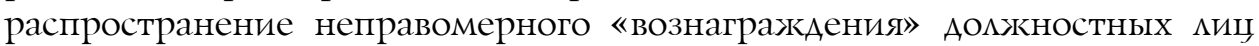
за их действия в рамках вполне законных обязанностей.

В первых десятилетиях XX в. меры юридической ответственности

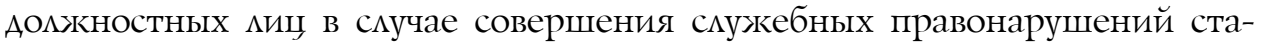
новятся более строгими. Наряду с уголовной ответственностью широко используется гражданская и дисциплинарная ответственность. Гражданская ответственность правонарушителей в области служебных преступлений назначалась вследствие определенного, особого порядка в судебном Аелопроизводстве. При подаче искового заявмения с требованием о компенсации ущерба ввиду осуществленного служебного правонарушения АОАжностными Аиџами среАних чинов к рассмотрению дела обычно поАключались в роли экспертов непосреАственные руководители виновного. Исковые заявления против высших чинов государственного аппарата требовали делопроизводства с участием и Гражданского кассационного, и Первого департаментов Сената, с обязательным надзором главы государс- 
тва. Широко применялись дисщиплинарные наказания рекомендательного характера, нацеленные на предотвращение и недопущение незаконных деяний должностными мицами. В ситуациях, когда фактами не было доказано служебное преступмение, но разбирательство присутствовало, чаще всего применялись штрафы в виде мишения части жалованья, перевод на Аругую, менее важную должность, освобождение от занимаемой Аолжности. Предупредительный характер таких дисциплинарных наказаний определялся и тем фактом, что подвергшиеся ответственности должностные миџа не имели права возразить или опротестовать примененное к ним Аисциплинарное наказание.

В целом Аеятельность в сфере пресечения служебных правонарушений в течение XIX - начала XX в. отличалась комплексностью и проводилась в отношении как органов государственной вмасти, так и органов местного самоуправления. ПреАставителям государственной власти было запрещено ведение хозяйственной деятельности - доходная часть государственных служащих подвергалась усиленному контролю. Измененная кадровая политика предусматривала более строгие требования к потенџиальным Аолжностным мицам на конкретные должности. Наблюдалось цогически справедливое применение юридической ответственности к правонарушителям-служащим: меры ответственности и наказания формировались исходя из предусмотренных и уголовных, и дисциплинарных мер. Но при этом неразрешенными остались вопросы достаточного финансового содержания государственных должностных миџ; наличия необходимого надзора со стороны обшества; неизменной всеАозволенности руководителя в рамках своего штата и сотрудников, что в совокупности обусловливало нивелирование действия превентивных мер по недопущению Аолжностных правонарушений.

Низкая эффективность организаџионно-правовой деятельности в указанный периоА в сфере борьбы с Аомжностными правонарушениями не позволила искоренить коррупционные проявления в Российской империи. ОАнако изученный практический опыт в борьбе с Аолжностными правонарушениями дает возможность провести сравнительный исторический и правовой анализ в области противодействия служебным правонарушениям с целью искоренения ошибок и проведения более эффективной нормотворческой и правоприменительной практики в современной России.

\section{Библиографический список}

1. Мнения гг. сенаторов по предмету соображения законов о истреблении лихоимства и лиходательства данные в 1825 и 1826 г. Правительствующего Сената в Общем Собрании Санкт-Петербургских Департаментов. СПб., 1827. Литера Б. С. 14-41.

2. Проект сенатора Корнилова касательно средств к прекращению лихоимства // Государственный архив Российской Федерации (далее-ГАРФ). Ф. 109. 1 эксп. 1826. Оп. 2. Д. 34. Л. 1-2. URL: https://statearchive.ru/383 
3. ГАРФ. Ф. 109. 1 эксп. 1831. Оп. 6. Д. 796. По представленной Государю Императору от министра внутренних дел записке о чиновниках, состоящих под надзором полиции. URL: https://statearchive.ru/383

4. Криминология: учебник для студентов вузов, обучающихся по специальности 021100 «Юриспруденция» / под ред. Г.А. Аванесова. М., 2011.

5. Катаев И.М. Дореформенная бюрократия по запискам, мемуарам и литературе. СПб., 1914.

6. Систематические ведомости о числе чиновников, судимых в уголовных палатах и равных им местах по преступлениям против должности за 1846-1849 гг. // Отчеты Министерства юстиции. СПб., 1835-1851.

7. Грибовский В.M. Государственное устройство и управление Российской империи. Одесса, 1912.

8. ГАРФ. Ф. 109. Оп. 2. Д. 34. Л. 1-2. URL: https://statearchive.ru

9. ГАРФ. Ф. 87. Д. 459. Л. 9. URL: https://statearchive.ru

10. Журнал МВД. СПб., 1858. № 5. URL: https://statearchive.ru

11. ГАРФ. Ф. 102. Оп. 61. Д. 10. Ч. 49. Л. 1-3. URL: https://statearchive.ru

12. ГАРФ. Ф. 102. Оп. 41. Д. 191. Л. 4-5. URL: https://statearchive.ru

13. Астатнин B.В. Борьба с коррупцией в России XVI-XX вв.: диалектика системного подхода. М., 2011.

14. ГАРФ. Ф. 109. ОП. 102. Д. 749. Л. 18. URL: https://statearchive.ru

15. Общая ведомость об оправданных и осужденных приговором окружных судов и судебных палат // Свод статистических сведений по делам уголовным, производящимся в 1873 г. в судебных учреждениях, действующих на основе уставов 20 ноября 1864 года. СПб., 1873. Ч. 2.

16. Газета «Гроза» (СПб.). 1911. 22 дек. 